\title{
The Lindsay Society for the History of Dentistry Annual Conference
}

By Brian Williams, Honorary Secretary of the Lindsay Society: the History of Dentistry

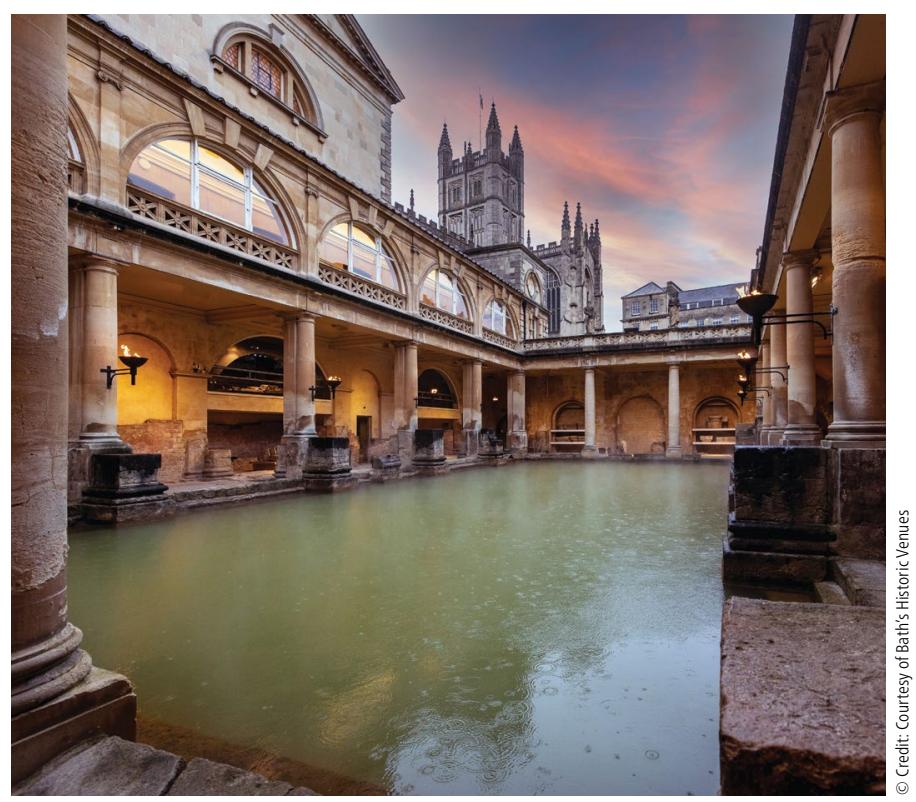

After a break of two years, the Lindsay Society's Annual Conference is back. Postponed from last year, the Bath conference in October will be better than ever. It will be based at the Doubletree by Hilton Hotel in the very heart of the city, giving easy access to the many sites of architectural and historical interest, not forgetting the world heritage site of the Roman Baths.

As with all good conferences, proceedings start in the bar on the Friday evening, welcoming friends and acquaintances before an excellent supper in the Hilton's renowned restaurant. The eclectic mix of lectures are spread over the Saturday and Sunday mornings which include Dentistry in the time of Jane Austen, Evolution of Oral Maxillofacial Surgery, the Royal Army Dental Corps and so much more. And, for the first time, the prestigious Lindsay Memorial Lecture will be given during the Annual Conference. Presented by Professor Jonathan Shepherd - Professor at the Crime and Security Research Institute at Cardiff University - on an alternative to 'A tooth for a tooth'. A subject of current importance, so a lecture not to be missed.

Perhaps the highlight of the weekend is always the Conference Dinner on the Saturday evening. This year will be no exception with a private tour of the Roman Baths followed by dinner in the Pump Rooms (pictured) overlooking this iconic world heritage pool.

So, when is this exciting weekend taking place? Starting on Friday evening, 15 October and going through until lunchtime on Sunday 17 October. For more information regarding the Lindsay Society's 2021 Conference go to www.bda.org/museum and follow the links to the Lindsay Society or contact the Honorary Secretary brianwilliams14@btinternet.com for even more information. 